\title{
La emigración como proceso de duelo. Protocolo de psicoterapia breve centrada en su elaboración ${ }^{1}$
}

RESUMEN. Se presenta un protocolo de psicoterapia breve para el tratamiento de pacientes emigrantes con el diagnóstico psicodinámico de "duelo no elaborado", explicando las características de dicho protocolo.

PALABRAS CLAVE: Emigración y duelo no elaborado. Protocolo psicoterapia breve.

\begin{abstract}
Presentation of a Brief Psychotherapy Protocol for the treatment of emigrant patients with the Psicodinàmic Diagnosis of "Pathological Grief", explaining the characteristics of such Protocol.
\end{abstract}

KEY WORDS: Emigration and Pathological Grief. Brief Psychotherapy Protocol.

\section{Introducción.-}

Habrá factores económicos, sociales y/o personales que originarán la idea de emigrar. Sin embargo, serán las motivaciones inconscientes (emociones y representaciones internas) las que harán dar el paso.

La emigración ha de incluir que "el lugar a donde se traslada el emigrante está lo suficientemente distante y por un tiempo prolongado como para que implique vivir en otra cultura y desarrollar en ella las actividades de la vida cotidiana, esto lleva implícito un cambio del medio externo en la continuidad del desarrollo personal"(1). La emigración, aunque sea voluntaria, es un proceso de cambio y pérdidas y pondrá en marcha todos los mecanismos implicados en el proceso de duelo, reactivándose la posición depresiva.

Como todo proceso de duelo, el de la emigración se inicia con el sentimiento de la pérdida de lo conocido y termina cuando se reintroyecta lo bueno de lo perdido y la valoración de la nueva cultura.

Parece confirmado (2)(3) que la emigración es un factor de riesgo psicopatológico, sobre todo si hay cierta vulnerabilidad en la estructura de personalidad del emigrante.

Estudios actuales sobre las emigraciones señalan que las consecuencias psicológicas de la emigración son diferentes según la edad, capacidad de contención de ambiente, lenguaje del nuevo medio... (2), y que "el duelo se puede postergar hasta la $2^{\mathrm{a}}$ generación" (1) o que "se necesitan tres generaciones para que se realice totalmente la elaboración del duelo”(3).

${ }^{1}$ Trabajo presentado en el XI Congreso de la Federación de Asociaciones Psicoanalíticas de España. Bilbao. Noviembre 1999. 
En este trabajo se presenta un "protocolo de psicoterapia breve centrada en la elaboración del duelo" como forma de tratamiento en la asistencia pública para los pacientes emigrantes con el diagnóstico psicodinámico de "duelo no elaborado" en los que dicho duelo se refiere al provocado por la emigración. Se explicarán las características de la psicoterapia breve que se realiza, centrándonos en los factores psicológicos individuales que están implícitos en la emigración y su repercusión en la estructura de personalidad del emigrante.

\section{2.- Emigración y personalidad.-}

Se parte de las ideas de M. Klein, ya que han sido sus estudios sobre la posición depresiva los que mejor han permitido comprender el duelo.

En su trabajo Duelo y su relación con los estados maníacos-depresivos (4) nos explica que cualquier pérdida o duelo que acontece en el desarrollo de la persona será una repeticióón del duelo normal ocurrido en la posición depresiva. Ella entiende por situación de duelo: "no sólo la relacionada con la pérdida del objeto amado, sino con cualquier dolor psicológico causado por experiencias penosas, sea cual sea su origen y características y que reactivarán la posición depresiva" (4), lo que implica que la posición depresiva nunca se elabora completamente. En el mismo artículo aclara que "en el duelo normal, el individuo reintroyecta y reinstala tanto a la persona real perdida, como a los padres amados que sintió como objetos internos buenos. En su fantasía, ese mundo interno (...) ha sido destruido cuando se produjo la pérdida actual (4) (...). La reconstrucción del mundo interno da la pauta del éxito de la labor de duelo" (4).

Y por último especifica que: "El duelo patológico es por no haber sido capaz la persona, en su temprana infancia, establecer objetos buenos internos y sentir seguridad en su mundo interno, es decir, no elaboraron la posición depresiva infantil” (4).

Aplicando dichas ideas al proceso de la emigración se puede decir que en toda emigración se reactivará la posición depresiva y surgirán todas las ansiedades, temores, etc. de dicha posición, se incrementan los sentimientos de persecución (aumenta la ambivalencia y la desconfianza) lo cual nos hace más difícil aceptar la nueva cultura con todas sus características y peculiaridades. Además la persona ha de enfrentarse a la pérdida de partes del self ligadas a los objetos perdidos (personas o situaciones sociales o profesionales).

El dolor experimentado se debe, sobre todo, a la necesidad de reconstruir el mundo interno que se siente fraccionado y la persona necesita instalar dentro de sí el objeto amado perdido y todo lo que proyectó en ella para así sentirse integrado. Esto es lo que desencadena el proceso de duelo y surgirán "todos los mecanismos implicados en dicho proceso, es decir, se reactivarán las ansiedades primitivas y se movilizarán los mecanismos de defensa que cada persona empleó en el enfrentamiento de sus primitivas situaciones infantiles de duelo" (2).

Sin embargo, hemos de tener presente que en la emigración no hay pérdida definitiva del objeto, éste permanece vivo, lo que favorece fantasías (conscientes e inconscientes) de reencuentro. 
Por todo ello, la elaboración del duelo en el emigrante dependerá de:

- Cómo ha elaborado la posición depresiva en su infancia.

- De su personalidad previa

- Del momento vital.

- De la realidad externa

- De la causa de la emigración.

En este trabajo se enfatizan fundamentalmente dos variables relacionadas con el proceso del duelo: la estructura de personalidad y el vínculo que se constituye con la realidad externa.

\subsubsection{Personalidad}

Según la estructura de personalidad, es decir, del tipo de vínculo que el emigrante estableció con sus objetos internos y si dicho vínculo le permitió poder integrar su Yo y distinguir entre fantasía y realidad externa, el emigrante tendrá la capacidad o no de elaborar esos cambios internos y externos que provoca la emigración.

Un ejemplo práctico podemos observarlo en el siguiente caso: Mujer de 37 años, casada, camarera de pisos, dos hijos. Emigró hace 8 años. Relata: "Desde hace cinco años que murió mi madre siento mucho dolor, no tengo ganas de nada, estoy triste, he adelgazado mucho, tiemblo mucho, tengo palpitaciones (...) No se murió en la operación, después le dio un infarto. Yo estaba allí, en casa y ella en el hospital. La noche antes soñé que me llamaba (...). Cuando la vi allí con tubos me mareé y no pude entrar a verla a cuidados intensivos (...) no me atreví a entrar (...) me siento culpable, no se si le fallé (...). Era muy buena con todo el mundo y sufría por todo. Sufría mucho porque mi padre bebe. No le pegaba, pero la insultaba (...). Siempre estaba mucho por mi. Decía: Mi niña (...). Ella no quiso venir porque tenía que cuidar a su hermano pequeño".

En el relato de la paciente parece implícito que el duelo por su madre ha reactivado un sentimiento de destrucción de su mundo interno, quizás como consecuencia de que el tipo de vínculo con la madre no le permitióó integrar su Yo.

Tizón y colaboradores (3) en el estudio que realizaron sobre "Migraciones y salud mental" expresan que: "En general cualquier trastorno de personalidad (DSM IV) implica un mal pronóstico para la elaboración del duelo migratorio".

Por otra parte Grinberg (5) apunta que las personalidades depresivas muestran una marcada intolerancia a la frustración, separaciones, pérdidas y experiencias de cambio en general, especificando que los rasgos de dependencia o apego ansioso (Bowlby) o la existencia de trastorno de personalidad dependiente son factores de mal pronóstico (1). Además, Grinberg y Grinberg nos hablan (1) de que los rasgos de personalidad que se hallan en la base de la formación de psicopatología en la emigración son: la envidia y la incapacidad de soportar la soledad.

Respecto a la envidia, M. Klein (4) aduce que es el sentimiento que implica deseos de agresión al otro por lo bueno que tiene, prefiriendo incluso la destrucción del objeto a disfrutar de él y sus cualidades.

Respecto a la soledad, existe capacidad para soportar la soledad cuando la persona ha podido introyectar un objeto "suficientemente bueno" que le permita dominar 
los celos, odios y envidia. En las primeras etapas de la migración, al llegar al país receptor es muy importante tener esta capacidad ya que al haber perdido las raíces y no existir vínculos en el país receptor hay una sensación de vacío que solo desaparecerá al integrarse en el nuevo medio.

Todo esto apoya la hipótesis psicoanalítica referente a la importancia que tienen los objetos primarios interiorizados desde las primeras épocas de nuestra vida para la estructuración y estabilidad de todo el conjunto de representaciones mentales que están en la base de nuestra capacidad de responder al conflicto.

\subsubsection{La realidad externa}

El proceso del duelo no es sólo un proceso intrapsíquico sino también vincular. Grinberg y Grinberg (1) apuntan al respecto que "La calidad del vínculo que pueda establecer la persona con su ambiente nuevo estará influenciada por las características de las relaciones objetales que haya tenido la persona antes de la emigración y por las de la comunidad que la recibe", es decir, una buena relación con la realidad externa fortalece al Yo y disminuye la ambivalencia y el miedo a ser destruido internamente.

Para conseguir esta relación y elaborar satisfactoriamente el proceso del duelo, el emigrante puede tener como factores de ayuda para la elaboración del duelo:

1.- Los grupos de emigrantes: que le ayudarán a neutralizar el miedo y la ansiedad ante lo nuevo y desconocido, como figuras confiables. Sin embargo, si la cohesión es excesiva dificultará la integración porque facilita la escisión entre las dos culturas(3).

2.- El trabajo, ya que reafirma la autoestima y tiene una función reparadora de lo que siente que ha abandonado y dañado en su país de origen.

3.- Una familia de origen estabilizada y cohesionada (Winnicott: "Unidad originaria" suficientemente estable y armónica). Sin embargo hemos de tener presentes que la emigración favorece el desarrollo de las instancias y núcleos fusionales simbióticos de la familia y también el cambio o reestructuración de roles paternos.

\section{3.- Etapas del proceso migratorio}

Tanto Tizón y colaboradores (3) como Grinberg y Grinberg (1) coinciden en describir varias etapas en el proceso de la emigración que van desde que se prepara la emigración, se realiza, la llegada al nuevo medio hasta la integración en la nueva cultura.

Cada una de estas etapas provocará ansiedades y defensas específicas:

$1^{a}$ etapa: Cuando se decide partir surgen ansiedades depresivas y culpa por lo que se ha decidido abandonar, sobre todo si la emigración es voluntaria (1). Las defensas que se manifiestan son, sobre todo, de tipo maníaco (negación omnipotente de la pérdida) manifestándose por desprecio del país de origen.

$2^{\text {a }}$ etapa: En el momento que llega al país de acogida surgen sobre todo ansiedades confusionales junto a persecutorias y depresivas. Las ansiedades confusionales se producen por la dificultad de diferenciar los sentimientos entre lo que se ha dejado y 
lo nuevo. Las ansiedades persecutorias surgen frente a las exigencias del nuevo medio (idioma, búsqueda de trabajo, vivienda, etc.).

En este momento la ayuda recibida del mundo exterior (trabajo, alojamiento, grupos de emigrantes, etc.) "contribuirá al relajamiento del control maníaco sobre el mundo interno" (3). Si no se da esa ayuda se incrementan las ansiedades paranoides y se utilizan mecanismos de defensa esquizoide (disociaciones: como la resistencia a aprender la nueva lengua), identificaciones proyectivas, idealizaciones compensatorias, etc.)

$3^{\text {a }}$ etapa: Si se produce la integración en la nueva cultura (elaboración del duelo) el emigrante habrá renunciado a algunas pautas de su cultura de origen para incorporar otras de la nueva cultura.

Un ejemplo que refleja este proceso sería el caso siguiente: Jéssica, 18 años. Hace cuatro meses que llegó a Mallorca, pero sus padres están aquí desde hace 2 años.

( $1^{\mathrm{a}}$ sesión) Ella dice que está triste porque ha tenido muchos cambios en los dos últimos años: no estoy adaptada (...) echo de menos a mis amigos. Me noto deprimida. No puedo arrancar en el trabajo, he encontrado trabajo de oficina, secretaria. ¿Deprimida? Tengo la sensación de soledad, me encierro (...) me siento sola aunque tengo a mi familia (...). Mis padres no entienden mi situación (...). No me preguntan cómo estoy (...) tienen miedo de que nos vayamos (...).

¿Fue decisión tuya venirte? Porque estaban mis padres. Allí el futuro no era bueno y no me podía quedar sola, mi familia estaba aquí.

( $6^{\mathrm{a}}$ sesión: seis meses): Ahora ya pensaría dos veces irme. Esto tiene cosas buenas y malas y allí también. Acá me da de comer este país y allí teníamos problemas. Esto, acá lo tengo que aceptar (...). Cuesta entender que volveré solo de visita.

Ahora extraño un poco menos (...) toda la familia extraña (...) nos juntamos con todos los argentinos y hablamos (...) estoy más animada.

Si la persona no es capaz de adaptarse al nuevo medio, es decir, no ha podido elaborar el proceso de duelo, se producirá una detención de su desarrollo que podrá manifestarse por síntomas psicosomáticos o mas graves (según la estructura de personalidad puede haber cuadros confusionales o brotes psicóticos), como explican Grinberg y Grinberg (1): En los duelos patológicos "la culpa persecutoria se observa en la clínica por presentar somatizaciones. Mas grave es cuando se producen Cuadros Melancólicos o Psicosis (...). La culpa depresiva se manifiesta por preocupación, pena y tendencia reparatoria auténtica".

El emigrante suele estar solo al llegar al nuevo medio, no puede dejar de trabajar y preocuparse por sus propios sentimientos por lo que es difícil que pueda elaborar el duelo y éste se posterga.

La descompensación se suele dar en personalidades que no han llegado a conseguir una diferenciación adecuada de sus objetos primarios, es decir, que no han elaborado suficientemente la Posición Depresiva. Esto unido a problemas externos (no han encontrado trabajo o sus expectativas no se han cumplido...) produce la crisis. 

se suele dar:

En el estudio de Tizón y colaboradores (3) explican que la descompensación

- Durante el asentamiento (primeros meses o un año).

- En el proceso de adaptación e integración (entre el $1^{\circ}$ y el $10^{\circ}$ año).

- A los 10 o más años.

En dicho estudio demostraron que la tríada que domina la expresión psicopatológica del emigrante es: depresión, hipocondría-somatización y paranoia (3) y que la somatización es una expresióón típica del duelo migratorio insuficientemente elaborado (3).

\section{4.- Psicoterapia breve centrada en la elaboración del duelo por la emigración.}

La unidad donde se realiza la atención a la salud mental está situada en una comarca turística de la isla de Mallorca, con muchos emigrantes de distintas regiones de España. Se detectó que muchos pacientes emigrantes presentaban síntomas psicosomáticos funcionales e inespecíficos, sentimientos de tristeza, muchas bajas laborales, etc..

Sus quejas solían ser, sobre todo, depresivas (de manera atípica) y somatoformes, además manifestaban ansiedad de tipo paranoico o persecutoria. Se pensó que todo ello reflejaba una mala elaboración del duelo que implica toda emigración. Se inició el estudio de varios pacientes y se decidió elaborar un Protocolo de Psicoterapia Breve Psicoanalítica focalizado en la elaboración del duelo causado por la emigración. A dicho protocolo lo denominamos "duelo no elaborado".

Pensamos que se podía realizar una psicoterapia breve psicoanalítica estructurando el proceso terapéutico en función de la técnica y modificando el encuadre.

Los pacientes a quienes iría dirigido este protocolo deberían reunir los siguientes requisitos:

- La emigración se había realizado como máximo hacía 3 años.

- Presencia de síntomas depresivos y psicosomáticos funcionales.

Los criterios de indicación mínimos para la realización de la psicoterapia breve psicoanalítica (propuestos tanto por Pérez Sánchez, A. (6) como por Tizón, San José y Nadal (7) y adaptados a nuestra unidad, fueron:

1. Motivación para el cambio

2. Capacidad de establecer vínculo.

3. Capacidad de insight y autoobservación.

4. Defensas no muy rígidas.

5. Tolerancia ante la ansiedad y la frustración.

En un primer momento, a través de las entrevistas diagnósticas, y en el inicio del proceso psicoterapeútico, el objetivo propuesto fue aumentar la capacidad de comprensión del paciente respecto a sus síntomas (somáticos y/o depresivos) para que pudiera vincularlos con los problemas derivados de la emigración (8). Es decir, la elaboración del duelo por la pérdida de lo que dejaron en el país de origen y (relacionado con ello) las dificultades de integración en el nuevo.

En las entrevistas diagnósticas se realizó la historia clínica:

1. - Anamnesis:

a) Psicopatología: motivo de consulta y por qué subjetivo de la enfermedad. 
b) Biografía (relatada espontáneamente por el paciente).

c) Familia de origen.

d) Familia actual

e) Vida laboral

f) Vida social

g) Sueños y recuerdos

2. - Diagnóstico psicodinámico:

a) Estructura de personalidad.

- Relación de objeto

- Formas básicas de vinculación

- Defensas

b) Ansiedades básicas

c) Capacidades yoicas

Valoramos la psicopatología en relación a la estructura de personalidad y ésta en función del tipo de relación de objeto predominante, analizando la forma de vinculación-separación del paciente.

De acuerdo a las posibilidades de nuestro espacio asistencial, se organizó el protocolo de la siguiente forma:

- Encuadre: duración 1 año. Frecuencia semanal. Duración dichas sesiones 30 minutos.

. El método y la técnica serán los propios de la psicoterapia breve psicoanalítica propuestos por Pérez Sánchez, A. (8): El terapeuta adopta una actitud activa, pero no directiva, dirigiendo sus intervenciones a la conexión entre el conflicto de separación/pérdida y las relaciones actuales (8).

- Foco terapéutico: Se concretó con cada paciente explicitándoselo a nivel de su conflicto relacional y de sus dificultades de separación.

En la clínica observamos ansiedades confusionales (de diferenciaciónindiferenciación), persecutorias y depresivas, por lo que se organizaban defensas: depresivas, maníacas, disociativas, obsesivas, reacción melancólica y/o regresión a la posición esquizoparanoide.

Los mecanismos de defensa que más se manifestaban eran: somatizaciones, escisión - disociación, proyección e identificación proyectiva, negación y control omnipotente del objeto.

El siguiente caso clínico ejemplifica las ansiedades y defensas que surgen cuando no se ha elaborado suficientemente la posición depresiva:

Mujer remitida por urgencias del Hospital con el diagnóstico de "Ideas de autolisis", con síntomas de labilidad emocional, llanto fácil, insomnio, anhedonia, ideas de muerte y autolíticas". En la primera sesión relata que "desde que murió mi madre (tenía 17 años) he estado deprimida. Tengo miedo a morirme, a tener lo de ella (...) nos están haciendo pruebas a todos los de la familia (...).Despierta muchas veces pienso que 
mi padre se muere o mi hija (...). Necesito que los demás me digan que soy normal, que no estoy loca, que soy buena (...) estoy a la defensiva, todo el mundo me cae fatal".

Sueño importante: “(El día antes de morir mi madre pintábamos su habitación en un tono azul celeste. De buenas a primeras ella se baja de la escalera y empieza a supurarle la herida. Yo intento calmarla y de buenas a primeras la veo agonizando y me desperté y me puse a gritar llamándola".

Mi primer trabajo fue a los 18 años cuidando a una señora mayor, pero yo no quería quedarme allí (Jerez) y me vine aquí porque estaban mis hermanos.

La paciente intentó "reparar" la culpa (depresiva) al morirse su madre cuidando a una persona mayor. Al no poder hacerlo aparece la culpa persecutoria manifestándose por somatizaciones.

En la psicoterapia breve psicoanalítica, al conseguir la elaboración de las ansiedades de separación, el paciente podrá integrar en su personalidad los aspectos que tenía disociados, reintroyectar las partes proyectadas y poder recuperar las cargas libidinales y de objeto necesarias para establecer vínculos nuevos.

La elaboración del duelo en la emigración conducirá al sentimiento de integridad personal enriquecida por todo lo que nos ofrece la nueva cultura y por un aumento de la confianza básica en nosotros mismos.

\section{Agradecimientos:}

A Antonio Pérez Sánchez por su apoyo y supervisión y a Joana Fornés por sus comentarios.

\section{BIBLIOGRAFÍA}

1. Grinberg L. y Grinberg R. Migración y Exilio. Madrid, Biblioteca Nueva, 1996

2. Calvo, F. Emigración y elaboración del duelo (Tesis Doctoral). Barcelona, Universidad Autónoma de Barcelona. Departamento de Psiquiatría, 1972.

3. Tizón, J.L. y colaboradores. Migraciones y Salud Mental. Un análisis psicopatológico tomando como punto de partida la inmigración asalariada de Cataluña. Barcelona, Promociones y Publicaciones Universitarias S.A., 1993.

4. Klein, M. Obras Completas. Barcelona, Piados, 1990.

5. Grinberg L. Psicoanálisis. Aspectos teóricos y clínicos. Barcelona, Piados, 1981.

6. Pérez Sánchez, A. Prácticas Psicoterapeúticas. Psicoanálisis aplicado a la asistencia pública. Barcelona, Fundación Vidal i Barraquer y Piados, 1996.

7. Tizón, J.L.; San José, J. y Nadal, D. Protocolos y Programas elementales para la atención primaria a la salud mental. Vol. I. Barcelona. Herder, 1997.

8. Pérez Sánchez, A. Elementos de Psicoterapia Breve Psicoanalítica. Barcelona, Fundación Vidal i Barraquer, 1992.

*Psicóloga clínica. Psicoterapéuta psicoanalítica

Dirección para correspondencia:

C/. Polvorín, 21 - Bajos - 07015-Palma (Baleares)

e-mail: issalsan@correo.corp.es

Fecha de recepción: 11-03-02 